\title{
Tetrandrine as a Therapeutic Agent for COVID-19
}

\author{
Paula Heister ${ }^{1}$ and Robin Poston $^{2}$ \\ ${ }^{1}$ Addenbrooke's Hospital \\ ${ }^{2}$ Queen Mary University of London
}

April 28, 2020

\begin{abstract}
More than one million patients worldwide have been diagnosed with coronavirus disease 19 (COVID-19) to date (WHO situation report, 8th April 2020). There is neither a vaccine to prevent infection with the causative organism, severe acute respiratory syndrome coronavirus 2 (SARS-CoV-2), nor a cure. In the struggle to devise potentially useful therapeutics in record time, the repurposing of existing drugs is a key route of action. In this review we argue that the bisbenzylisoquinoline and calcium channel blocker tetrandrine, originally extracted from the plant Stephania tetrandra and utilised in traditional Chinese medicine, could be repurposed to treat COVID-19. We collate and review evidence for tetrandrine's putative mechanism of action in viral infection, specifically its recently discovered antagonism of the two-pore channel 2 (TPC2). Consideration of its pharmacodynamics and pharmacokinetics suggests that oral tetrandrine at doses currently used in clinical practice could be an effective agent for the treatment of SARS-CoV-2 infection in humans.
\end{abstract}

\section{Tetrandrine as a Therapeutic Agent for COVID-19}

P. M. Heister ${ }^{1,+}$, University of Cambridge

R. N. Poston ${ }^{2,+}$, Queen Mary University of London

1 ph535@cam.ac.uk

2 r.poston@qmul.ac.uk

+ The authors contributed equally to this work

Running Head: Tetrandrine for COVID-19

Key words: coronavirus, SARS-CoV-2, two-pore channel 2 (TPC2), endolysosomal pathway, calcium channel blocker, drug repurposing, pharmacodynamics, pharmacokinetics, clinical trial, traditional Chinese medicine.

Word count: 1861

Figure count: 1

Introduction

We wish to draw attention to the possibility of repurposing the existing calcium channel blocking drug tetrandrine for the treatment of severe acute respiratory syndrome coronavirus 2 (SARS-CoV-2) infection.

Tetrandrine is a bisbenzylisoquinoline that can be extracted from the perennial vine plant Stephania tetrandra S. Moore (Chinese patent WO2004009106A1, 2002), which has been used in traditional Chinese medicine ([1], [2] and references therein). It can also be synthesised chemically (US Patent 10,023,584 B2, 2018, [3]) . 
There is extensive literature on the anti-inflammatory, immunosuppressive, oncological and cardiovascular effects of tetrandrine [2;4-6]. It is licensed in China for the treatment of silicosis, but to our knowledge has not been licensed for viral illnesses in any country to date.

\section{Mechanism of Action}

The putative mechanism of action of tetrandrine that underlies its potential use as a coronavirus disease 2019 (COVID-19) treatment is its ability to block the two-pore channel 2 (TPC2) in host cells and thus inhibit virus replication at low micromolar concentrations [7]. However, it has been reported also to block other targets, including L- and T-type calcium channels ([2], [8], and references therein).

Two-pore channels (TPCs) are intracellular calcium/cation channels located in the membranes of host endolysosomal compartments which SARS-CoV-2, the virus causing COVID-19 (and several other viruses) depend upon for egress from these organelles and replication. TPC2 has already been implicated in Middle East Respiratory Syndrome-Coronavirus (MERS-CoV) [9], Ebola virus (EBOV) [10], and Merkel cell polyoma virus (MCPyV) [11] infection as a key drug target.

There are specific TPC blocking agents (such as Ned-19, [12]), which have been shown to inhibit EBOV replication in vitro [10], but are currently only chemical tools, though they may engender drug candidates in the future. The different stereoisomers of Ned-19 can have different effects in vitro and their respective effects may differ according to tissue type $[12 ; 13]$.

However, many existing calcium channel antagonists block TPCs at relatively high concentrations (for example nifedipine, verapamil, etc. [14;15], and references therein), and there is evidence that such calcium channel blockers (CCBs) could be repurposed in viral illnesses [16;17]. While these are attractive candidates for repurposing due to their widespread use; their efficacy with respect to SARS-CoV-2 infection needs further investigation in the first instance.

Tetrandrine, while also not specific to TPC2 [2], shows greater efficacy in vitro against MERS-CoV than other CCBs [9]. It also decreased human coronavirus strain OC43 (HCoV-OC43) infection of MRC-5 human lung cells in vitro, with an inhibitory concentration $\left(\mathrm{CC}_{50}\right)$ of $0.33 \mu \mathrm{M}$, lower than that of related alkaloids [18]. Critically, tetrandrine was found recently to be effective against SARS-CoV-2 in vitro [7].

\section{Administration and Dosage}

It has been suggested that a $90-99 \%$ reduction of viral replication is required for effective therapy of quickly progressing acute viral infections; the general standard for chronic viral infections being $50 \%$ [19]. The dose for a $90 \%$ reduction of SARS-CoV-2 pseudovirus replication in vitro was shown to be approximately 3 $\mu \mathrm{g} / \mathrm{ml}[7]$.

Tetrandrine has been reported to be poorly soluble (saturation is $0.015 \mathrm{mg} / \mathrm{ml}$ in phosphate buffered saline at $\mathrm{pH}$ 7.4), and to have low and variable oral bioavailability (cited in [20], and references therein). Pharmaceutical methods have thus been investigated to improve the bioavailability; including lipid nanocapsules, nanoparticles, ethosomes, and microspheres [20]. Tetrandrine has also been administered by inhalation in humans with a metered dose inhaler for the treatment of asthma (reviewed in [21], original not available).

Administration in mice of $30 \mathrm{mg} / \mathrm{kg}$ tetrandrine intraperitoneally, a frequently-used dose in animal studies, was shown to give a peak plasma concentration of $2 \mu \mathrm{M}(1.2 \mu \mathrm{g} / \mathrm{ml})$ [22], whilst $10 \mathrm{mg} / \mathrm{kg}$ of oral tetrandrine resulted in a peak plasma concentration of $500 \mathrm{ng} / \mathrm{ml}$ in rats [20]. If the drug was emulsified, the same dose gave a peak concentration of $1.2 \mu \mathrm{g} / \mathrm{ml}$ [20]. Pharmacodynamic studies in human subjects [23] showed that a single oral dose of $100 \mathrm{mg}$ tetrandrine produced an average maximal serum concentration of $67.26 \mathrm{ng} / \mathrm{ml}$ $(\mathrm{n}=6)$. However, these data require confirmation, as there seems to be a discrepancy between this value and a graph in the same publication.

In rats, the average maximal serum concentration obtained after inhalation of $8 \mathrm{mg} / \mathrm{kg}$ of tetrandrine was $140 \mathrm{ng} / \mathrm{ml}$. While this serum concentration was moderate, average maximal wet lung tissue concentration obtained at post mortem examination following inhalation of the same dose of tetrandrine was over 90 
$\mu \mathrm{g} / \mathrm{g}$. Lung concentrations following intravenous administration of $7.5 \mathrm{mg} / \mathrm{kg}$ were also relatively high with an average maximal concentration of $\sim 20 \mu \mathrm{g} / \mathrm{g}$ [24]. In another study investigating the spatiotemporal distribution of tetrandrine in rats using mass spectrometry imaging, $30 \mathrm{mg} / \mathrm{kg}$ intravenous administration also resulted in high drug concentrations specifically in the lungs with a peak of $120 \mu \mathrm{g} / \mathrm{g}$ [25].

The above data suggest that tetrandrine may reach therapeutic concentrations in lung tissue even when serum concentrations remain relatively low. This is in keeping with its two compartment kinetic profile and high apparent volume of distribution (though up to $90 \%$ of the drug can be plasma protein bound; [2], and references therein).

Toxic doses have been reported in an MRC-5 human lung cell line study with cytotoxic concentration $\left(\mathrm{CC}_{50}\right)$ $>10 \mu \mathrm{M}[18]$. Similar results were reported in WI-38 human lung fibroblast and NL-20 human bronchial epithelial cell lines [26] In animal experiments, the reported median lethal dose $\left(\mathrm{LD}_{50}\right)$ for oral administration was $3700 \mathrm{mg} / \mathrm{kg}$ in mice and $2230 \mathrm{mg} / \mathrm{kg}$ in rats (cited in [6]). Acute lung injury was demonstrated in mice at a dose of $150 \mathrm{mg} / \mathrm{kg}$ intraperitoneally [26]. Toxic effects of tetrandrine in humans have been reported with $10 \mathrm{mg} / \mathrm{kg}$ intravenous administration (cited in [2] and [6]).

According to the above-mentioned Chinese patent (WO2004009106A1, 2002), dosage in humans is usually in the range of $0.02-1.5 \mathrm{~g} /$ day depending on the weight and symptoms of the patient. Tetrandrine has been used at an oral dose of $60-100 \mathrm{mg}$ three times a day in recent studies on silicosis ([27], [28]), and at 60 mg four times a day in an ongoing clinical trial (see below). In intravenous administration in humans, doses between $240 \mathrm{mg}$ and $300 \mathrm{mg}$ have been described as a 'safe range' (cited in [6], original not available). The maximum utilised doses in human studies that could be found were $200 \mathrm{mg}$ orally three times a day (cited in [2]), and $400 \mathrm{mg}$ three times a day with the route of administration not stated (cited in [6]).

It is difficult to conduct relevant animal to human dose conversions given the lack of in vivo studies of tetrandrine in SARS-CoV-2 infection and the lack of lung concentration data for oral administration of tetrandrine. The following human equivalent dose (HED) calculation serves only to illustrate that established clinical doses of tetrandrine in humans are likely to lead to potentially effective doses for viral inhibition in lung, as based on animal/cell line studies. The HED of a $7.5 \mathrm{mg} / \mathrm{kg}$ intravenous dose in rat (shown to give rise to lung concentrations of tetrandrine many times that required for a $90 \%$ reduction of SARS-CoV-2 pseudovirus replicationin vitro ) is $\sim 1.21 \mathrm{mg} / \mathrm{kg}$ [29], i.e. $\sim 72.6 \mathrm{mg}$ for a standard $60 \mathrm{~kg}$ human. This is well below reported toxic doses in humans, and even with low bioavailability should be achievable with oral equivalent doses in the range of the above mentioned clinical trial (240 mg/day in divided doses).

\section{Potential for the Use of Tetrandrine in the Treatment of SARS-CoV-2 Infection}

It is probable from the available evidence that oral tetrandrine could be an effective agent for the treatment of SARS-CoV-2 infection in humans.

The level of inhibition of viral replication in lung attainable with standard oral dosing of tetrandrine could be of value for the treatment, or potentially the prophylaxis (pending caveats about long-term use and toxicity) of SARS-CoV-2 infection. Prophylaxis is suggested because early administration of tetrandrine relative to infection has been shown to be more effective in vitro in the context of $\mathrm{HCoV}-\mathrm{OC} 43$ [18] and this may also apply to SARS-CoV-2.

As tetrandrine is already licensed and used in China as an oral tablet at the doses cited above, it is probable that these doses are safe to be administered more widely. However, evidence of conclusive pharmacokinetic and toxicological studies, as well as clinical trials are required.

Additionally, as tetrandrine is likely to operate in a different manner to antiviral agents currently being considered for the treatment of SARS-CoV-2 infection, it might make for a suitable synergistic adjunct. The administration of tetrandrine using inhalation by aerosol also stands a possibility of being effective and would have the advantage of direct delivery to the key site of infection. However, this requires further research.

\section{Ongoing Research and Availability}


There are currently no CCBs on the WHO list of drug candidates for SARS-CoV-2 infection:

https://www.who.int/blueprint/priority-diseases/key-action/Table_of_therapeutics_Appendix_17022020.pdf?ua=1.

To date, there is at least one clinical trial registered that employs CCBs in the context of COVID-19 (NCT04330300, Galway, Ireland). It is based around the observation that SARS-CoV-2 uses angiotensin converting enzyme 2 (ACE2) as a cell entry point, and that commonly prescribed antihypertensives, angiotensin converting enzyme inhibitors (ACE inhibitors) might have a detrimental effect on patients who contract COVID-19. The study thus compares patients who remain on ACE inhibitors throughout their illness with patients who are switched to alternative antihypertensives, including CCBs. While this work is not concerned with the mechanism of action discussed above, it will provide useful information on the potential therapeutic role of these drugs in SARS-CoV-2 infection.

No patents specifically relating to tetrandrine and the therapy of SARS-CoV-2 infection were found online (but see Chinese and US patents, cited above). However, a phase 4 clinical trial of tetrandrine for the treatment of SARS-CoV-2 was set up in China in March 2020, https://clinicaltrials.gov/ct2/show/NCT04308317, of one year's duration. It is geared towards preventing pulmonary fibrosis, and does not mention a pharmacological basis for the mechanism of action of tetrandrine. However, primary and secondary outcome measures are stated as survival rate and body temperature, respectively, suggesting that the trial will provide valuable insights into the role of tetrandrine as an acute therapeutic agent.

\section{Suggested Actions}

The following is a non-exhaustive list of suggested studies that could be considered at this point:

1. Confirmatory pharmacokinetic and toxicological studies of oral tetrandrine

2. A clinical trial to investigate tetrandrine's potential, using a standard oral dose, as an acute therapeutic or prophylactic agent against SARS-CoV-2 infection, provided safety can be confirmed for the particular length of use

3. In vitro investigations to assess the potential of other calcium channel blockers known to block TPCs, such as nifedipine or verapamil, to inhibit SARS-CoV-2 pseudovirus replication

4. If indicated by (3), a clinical trial to investigate the potential role of clinically established calcium channel blockers such as nifedipine or verapamil as therapeutic agents in SARS-CoV-2 infection

5. A retrospective analysis of the relative outcomes of COVID-19 patients already on CCBs

6. In vitro investigations to assess the potential of analogues of Ned-19 and other chemicals with expected specificity as TPC inhibitors to inhibit SARS-CoV-2 pseudovirus replication

7. An autopsy toxicology study to assess tetrandrine (or other calcium channel blocker) concentration in human lung tissue in patients prescribed these drugs during life

\section{Acknowledgements}

The authors have no competing financial interests.

We would like to thank Professor Antony Galione, Department of Pharmacology, University of Oxford, for helpful discussions; and Kiera Jamison, for the co-production of Fig. 1.

Correspondence should be addressed to Dr Paula Heister (ph535@cam.ac.uk) or Dr Robin Poston (r.poston@qmul.ac.uk).

\section{Reference List}

1. Chen KK, Chen AL: The alkaloids of han-fang-chi . J Biol Chem 1935, 109: 681-685.

2. Huang Y-T, Hong C-Y: Tetrandrine . Cardiovascular Drug Reviews 1998, 16: 1-17.

3. Schutz R, Meixner M, Antes I, Bracher F: A modular approach to the bisbenzylisoquinoline alkaloids tetrandrine and isotetrandrine .Org.Biomol.Chem 2020.

4. Chen Y, Tsai YH, Tseng SH: The potential of tetrandrine as a protective agent for ischemic stroke. Molecules. 2011,16: 8020-8032. 
5. Bhagya N, Chandrashekar KR: Tetrandrine and cancer - An overview of the molecular approach . Biomedicine \& Pharmacotherapy 2018, 97: 624-632.

6. Shangbin Q. Hanfanji. pp400-410. Pharmacology and application of Chinese materia medica ,, Vol 1. Eds., Chang, H-M., and But, P. P-H, World Scientific, 1986.

7. Ou X, Liu Y, Lei X, Li P, Mi D, Ren L, Guo L, Guo R, Chen T, Hu J, Xiang Z, Mu Z, Chen X, Chen J, Hu K, Jin Q, Wang J, Qian Z:Characterization of spike glycoprotein of SARS-CoV-2 on virus entry and its immune cross-reactivity with SARS-CoV . Nat.Commun.2020, 11: 1620.

8. King VF, Garcia ML, Himmel D, Reuben JP, Lam YK, Pan JX, Han GQ, Kaczorowski GJ: Interaction of tetrandrine with slowly inactivating calcium channels. Characterization of calcium channel modulation by an alkaloid of Chinese medicinal herb origin . J Biol Chem 1988, 263: 2238-2244.

9. Gunaratne GS, Yang Y, Li F, Walseth TF, Marchant JS:NAADP-dependent Ca(2+) signaling regulates Middle East respiratory syndrome-coronavirus pseudovirus translocation through the endolysosomal system . Cell Calcium 2018, 75: 30-41.

10. Sakurai Y, Kolokoltsov AA, Chen CC, Tidwell MW, Bauta WE, Klugbauer N, Grimm C, Wahl-Schott C, Biel M, Davey RA: Ebola virus. Two-pore channels control Ebola virus host cell entry and are drug targets for disease treatment . Science 2015,347: 995-998.

11. Dobson SJ, Mankouri J, Whitehouse A: A requirement for potassium and calcium channels during the endolysosomal trafficing of polyomavirus virions . bioR.xiv preprint 2019.

12. Naylor E, Arredouani A, Vasudevan SR, Lewis AM, Parkesh R, Mizote A, Rosen D, Thomas JM, Izumi M, Ganesan A, Galione A, Churchill GC:Identification of a chemical probe for NAADP by virtual screening . Nat.Chem Biol 2009, 5: 220-226.

13. Trufanov SK, Rybakova EY, Avdonin PP, Tsitrina AA, Zharkikh IL, Goncharov NV, Jenkins RO, Avdonin PV: The Role of Two-Pore Channels in Norepinephrine-Induced $[\mathrm{Ca}(2+)]$ i Rise in Rat Aortic Smooth Muscle Cells and Aorta Contraction . Cells 2019,8 .

14. Genazzani AA, Mezna M, Dickey DM, Michelangeli F, Walseth TF, Galione A: Pharmacological properties of the Ca2+-release mechanism sensitive to NAADP in the sea urchin egg . Br.J Pharmacol. 1997, 121: 1489-1495.

15. Rahman T, Cai X, Brailoiu GC, Abood ME, Brailoiu E, Patel S:Two-pore channels provide insight into the evolution of voltage-gated $\mathbf{C a}+$ and $\mathrm{Na}+$ channels . Sci.Signal. 2014,7: ra109.

16. Chen X, Cao R, Zhong W: Host Calcium Channels and Pumps in Viral Infections . Cells 2019, 9 .

17. Li H, Zhang LK, Li SF, Zhang SF, Wan WW, Zhang YL, Xin QL, Dai K, Hu YY, Wang ZB, Zhu XT, Fang YJ, Cui N, Zhang PH, Yuan C, Lu QB, Bai JY, Deng F, Xiao GF, Liu W, Peng K: Calcium channel blockers reduce severe fever with thrombocytopenia syndrome virus (SFTSV) related fatality . Cell Res. 2019, 29: 739-753.

18. Kim DE, Min JS, Jang MS, Lee JY, Shin YS, Song JH, Kim HR, Kim S, Jin YH, Kwon S: Natural BisBenzylisoquinoline Alkaloids-Tetrandrine, Fangchinoline, and Cepharanthine, Inhibit Human Coronavirus OC43 Infection of MRC-5 Human Lung Cells .Biomolecules. 2019, 9: 696.

19. Falzarano D, Feldmann H: Virology. Delineating Ebola entry .Science 2015, 347: 947-948.

20. Liu C, Lv L, Guo W, Mo L, Huang Y, Li G, Huang X:Self-Nanoemulsifying Drug Delivery System of Tetrandrine for Improved Bioavailability: Physicochemical Characterization and Pharmacokinetic Study . Biomed.Res.Int. 2018,2018: 6763057. 
21. Xie QM, Tang HF, Chen JQ, Bian RL: Pharmacological actions of tetrandrine in inflammatory pulmonary diseases. Acta Pharmacol.Sin. 2002, 23: 1107-1113.

22. Dai CL, Xiong HY, Tang LF, Zhang X, Liang YJ, Zeng MS, Chen LM, Wang XH, Fu LW: Tetrandrine achieved plasma concentrations capable of reversing MDR in vitro and had no apparent effect on doxorubicin pharmacokinetics in mice . Cancer Chemother.Pharmacol. 2007,60: 741-750.

23. Yang G, Zhang C, Hu P, Zhu M, Hu M, Gao S: An UPLC-MS/MS method for quantifying tetrandrine and its metabolite berbamine in human blood: Application to a human pharmacokinetic study .J.Chromatogr.B Analyt.Technol.Biomed.Life Sci. 2017,1070: 92-96.

24. Su W, Liang Y, Meng Z, Chen X, Lu M, Han X, Deng X, Zhang Q, Zhu H, Fu T: Inhalation of Tetrandrine-hydroxypropyl-beta-cyclodextrin Inclusion Complexes for Pulmonary Fibrosis Treatment . Mol.Pharm.2020.

25. Tang W, Chen J, Zhou J, Ge J, Zhang Y, Li P, Li B:Quantitative MALDI Imaging of Spatial Distributions and Dynamic Changes of Tetrandrine in Multiple Organs of Rats . Theranostics.2019, 9: 932-944.

26. Jin H, Li L, Zhong D, Liu J, Chen X, Zheng J: Pulmonary toxicity and metabolic activation of tetrandrine in CD-1 mice .Chem Res. Toxicol. 2011, 24: 2142-2152.

27. Sun J, Song P, Wang Y, Chen Y: Clinical efficacy of acetylcysteine combined with tetrandrine tablets in the treatment of silicosis and the effect on serum IL-6 and TNF-alpha .Exp. Ther.Med. 2019, 18: 3383-3388.

28. Zhang J, Wang Y, Zhang S, Li J, Fang H: Effects of tetrandrine combined with acetylcysteine on exercise tolerance, pulmonary function and serum TNF-beta1 and MMP-7 in silicosis patients .Exp.Ther.Med. 2020, 19: 2195-2201.

29. U.S.Department of Health and Human Services Food and Drug Administration Center for Drug Evaluation and Research (CDER). Guidance for Industry.Estimating the Maximum Safe Starting Dose in Initial Clinical Trials for Therapeutics in Adult Healthy Volunteers . 2005. https://www.fda.gov/media/72309/dowl

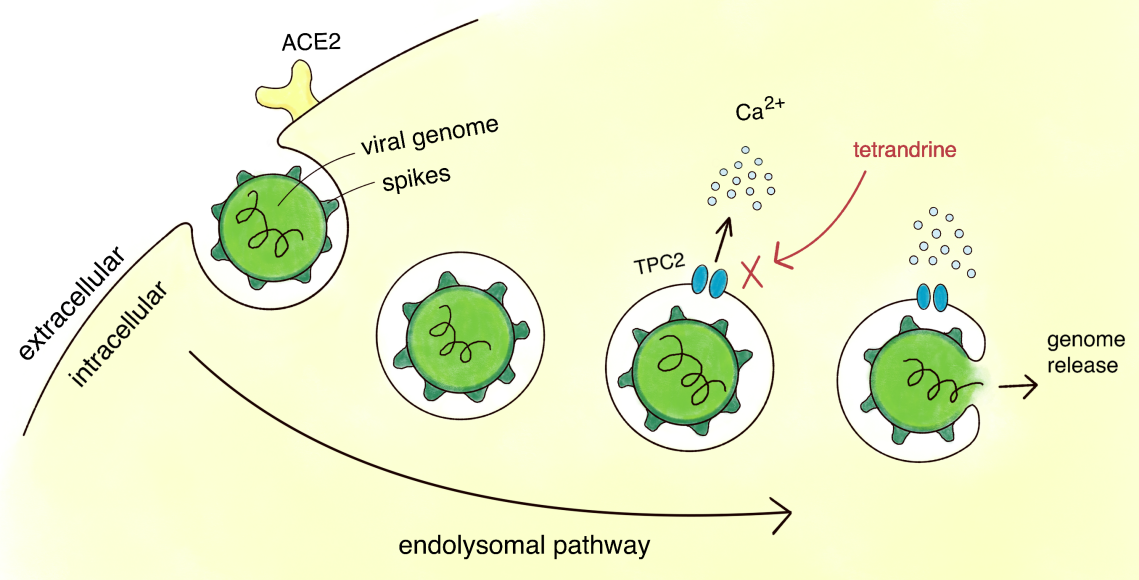

